\title{
Evaluation of Stream Gauge Density and Implementing the Concept of Virtual Gauges in Northern Ontario for Watershed Modeling
}

\author{
Elizabeth Philip and Jim McLaughlin \\ Ontario Ministry of Natural Resources and Forestry, Peterborough, Ontario
}

\begin{abstract}
A balanced stream gauge network design is required to establish scientifically defensible baseline hydrological conditions in order to simulate their future responses to changes in climate and land use practices. The objectives of this study were twofold. The first objective was to evaluate Water Survey of Canada's HYDAT stream gauge density in Northern Ontario watersheds against World Meteorological Organisation (2008) guidelines. The second objective was to implement the concept of virtual gauges into the stream network. The virtual gauges represented are the discontinued gauges. Monthly mean streamflow was re-constructed for nine virtual gauges up to 2015 , reducing the extent of data needs. The re-constructed data were tested using the coefficient of determination. Mean annual flow, annual and summer runoff coefficients, and derivatives of annual flow duration curves were used to describe the suitability of the data for watershed modeling. Our network design is cost efficient, suitable for the landscape and optimizes available hydrologic information to support the Government of Ontario's Far North Land Use Planning Initiative.
\end{abstract}

\section{Introduction}

The hydrometric data collected from a stream gauge network is used by different sectors: agriculture, forestry, transportation, oil and gas, mining, fisheries, hydropower, sewage treatment, water supply, flood mitigation, resource management, and government programs (Azar et al. 2003). Over the past century, numerous surface water gauging stations were established in Ontario. However, with rationalization, many gauges were discontinued. The historic data collected from these discontinued gauges is not being utilized for the purposes of water management, land use planning, or modeling. This study evaluates the stream gauge density and reconstructs the streamflow, by reconceptualising the old network design, and summarizes the data for use in hydrologic and hydraulic modeling.

The objectives of this study are: to evaluate the stream gauge density of the southwestern Hudson Bay and Nelson River watersheds based on World Meteorological Organisation (WMO) 2008 guidelines (WMO 2008); and to reconstruct, up to 2015, the monthly mean streamflow of discontinued stream gauges with active long term base gauges by implementing the concept of virtual gauges in network design.

This study is important as it details an approach to maximizing the use of available hydrologic information and highlights the science gap in Northern Ontario when planning land development in watersheds. This study was initiated as part of the Ontario Government's Far North Land Use Planning Initiative (OMNRF 2014).

\section{Methodology}

\subsection{Data Sources and Study Area}

The data used for the study includes streamflow data and watershed polygons. The National Hydrometric Program is responsible for collecting, interpreting and disseminating standardized information concerning surface water quantity across Canada. Under the authority of the Canada Water Act (1971), Environment and Climate Change Canada's Water Survey of Canada section (WSC), provincial governments and other agencies cost share (under bilateral agreements) and operate ISO 9000 compliant HYDAT stream gauges.

Canada has Reference Hydrometric Basin Network (RHBN) benchmark stations. These RHBN stations are established in areas that are relatively uninfluenced by past or future anthropologic changes. Higher quality records covering long time periods under natural conditions are the essence of RHBN gauge data. The stations complement Canada's Reference Climate Station network and can be used to address climate change and variability (Environment Canada 2010; 2012; Whitfield et al. 2012). The archived data from WSC constitutes the streamflow record (WSC 2016).

Philip, Elizabeth and Jim McLaughlin. 2018. Evaluation of Stream Gauge Density and Implementing the Concept of Virtual Gauges in Northern Ontario for Watershed Modeling. Journal of Water Management Modeling 26:C438.

https://doi.org/10.14796/JWMM.C438 @ CHI 2018. www.chijournal.org ISSN 2292-6062. 
The Ontario Integrated Hydrology $(\mathrm{OIH})$ package is a suite of spatial datasets published by the Ontario Government. The $\mathrm{OIH}$ data package is used to define homogenous regions and to delineate watersheds (OMNRF-OIH 2012).

The study area consists of those parts of the southwestern Hudson Bay and Nelson River watershed systems that lie within the province of Ontario. The map (Figure 1) shows the location of both active and discontinued stream gauges and the OIH data package watershed polygons. Table 1 shows the major rivers for each of the polygons.

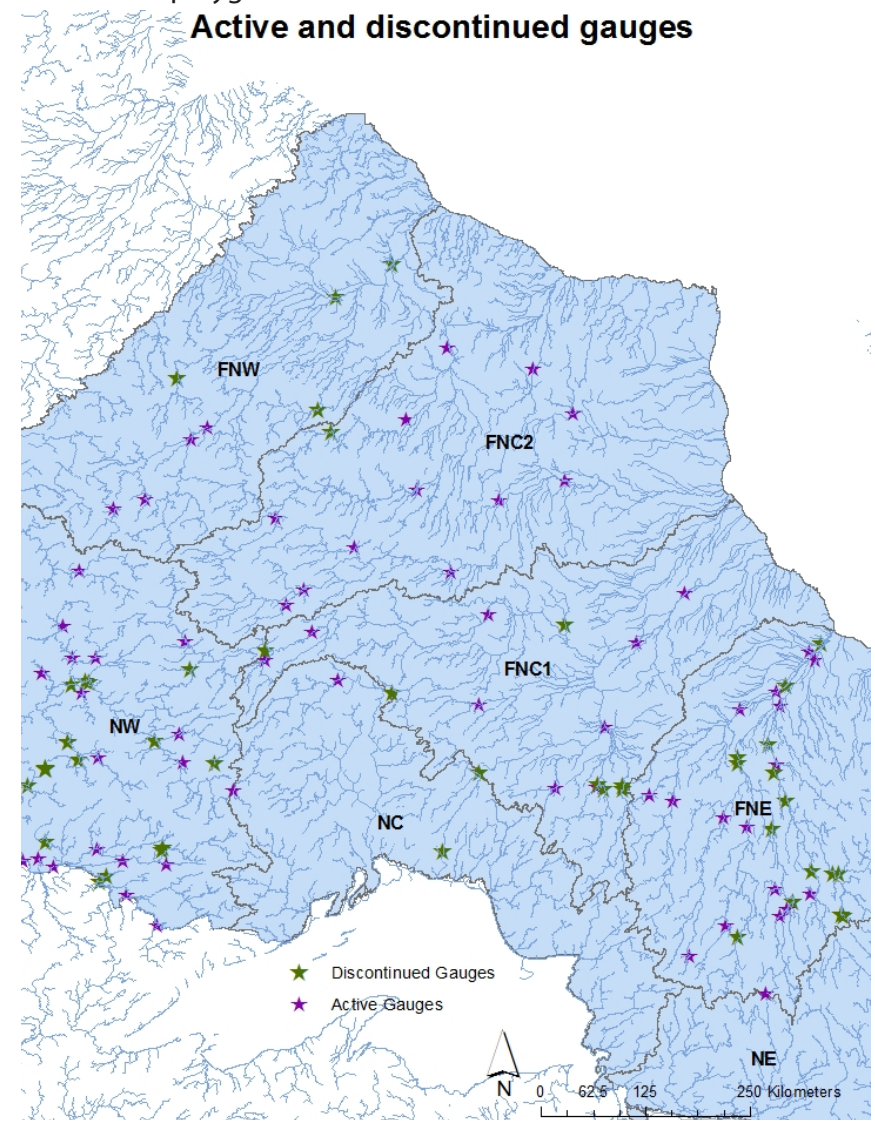

Figure 1 Map showing the locations of the active and discontinued stream gauges within the study area.

Table 1 Major rivers in the $\mathrm{OIH}$ data package watershed polygons.

\begin{tabular}{lcc}
\hline \multicolumn{1}{c}{ Package Name } & Abbreviated Name & Major Rivers \\
\hline Far North Central 1 & FNC1 & Albany \\
& & Kenogami \\
Far North Central 2 & FNC2 & Ekinisk \\
& & Ekwan \\
Far North East & FNE & Moose \\
& & Missinaibi \\
& & Mattagami \\
Far North West & & Abitibi \\
& FNW & Hayes \\
North West & NW & Severn \\
& & Winnipeg \\
\end{tabular}

\subsection{Review of Network Studies and History of the Number of Gauges}

The first network study was published as Planning of a Hydrometric Network for the Province of Ontario in 1969 (Shawinigan Engineering Company, Ltd 1969). The scope of the study was to examine and evaluate the hydrometric network for Ontario and to make recommendations to physically expand the network for adequate coverage of long term hydrometric data gathering. The study resulted in an increase in the number of stream gauges installed across the province.

During the 1980s and 1990s budgetary constraints caused a reduction in the resources expended on data collection programs. In response to decreased budgets, a water monitoring program re-engineering strategy was developed that was based on seven key items: rationalization, integrated planning, harmonization, modernization, commercial services, organization, and people. The project was undertaken by Dillon Consulting in 1996 and the report was titled Rationalization of Surface Water Monitoring Stations for Flood Management and Water Related Resource Management (Dillon Consulting 1996). The rationalization resulted in a reduction in the number of gauges.

In the late 1990s, following this period of reduction, the number of stations began to increase. The need for flood data and other hydrometric data was identified, and as a result new stations were introduced. As the new stations were installed in the network, an additional study titled Review and Analysis of Stream Gauge Networks for Ontario Stream Gauge Rehabilitation Project was completed (Pyrce 2004).

In 2010 Environment and Climate Change Canada studied the gauge density, using the WMO (1981) guidelines which report density in gauges $/ 1000 \mathrm{~km}^{2}$, the same unit of measure used in WMO (2008). The 2010 stream gauge density reported was 0.29 for Canada.

Other studies in Canada include Evaluation of Canadian National Hydrometric Network Density Based on WMO (2008) Standards (Coulibaly et al. 2013), in which density was estimated based on eco-districts. This study excluded eight eco-districts located in the Hudson Bay drainage area which were classified as interior plains.

A notable study was done in British Columbia in which the benefit:cost ratio for a hydrometric network was evaluated. The ratio obtained was 19:1, which means that for every dollar spent, a benefit of $\$ 19$ was returned. With adequate network density, the economic benefit to the region that was studied would triple (Azar et al. 2003).

The bar chart (Figure 2) shows the varying numbers of gauges that were added during each decade and the gauges that are active now. Of the total of 116 gauges installed, only 65 gauges are now active and the remaining 51 gauges are discontinued. How to utilize the data from the discontinued gauges and how to assess the feasibility of statistical methodology on the network design in this landscape (Langbein 1954; Mishra and 
Coulibaly 2008) form the basis of the second objective of this study. The distribution of the gauges based on the period of record is shown in Table 2. There are few newly installed gauges and five gauges with $\geq 100 \mathrm{y}$ of record.

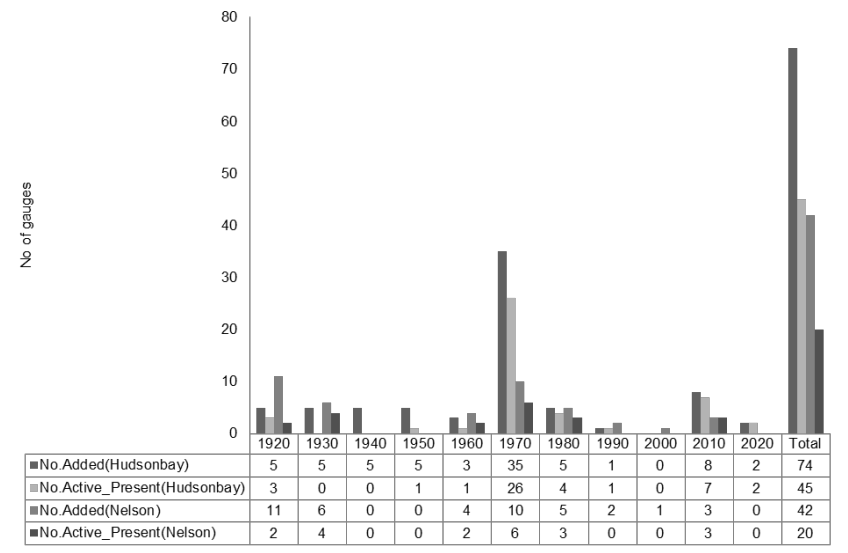

Figure 2 History of hydrometric network.

Table 2 Distribution of gauges based on the period of record.

\begin{tabular}{cc}
\hline No of Years & No of gauges \\
\hline $0-10$ & 10 \\
$11-20$ & 5 \\
$21-30$ & 4 \\
$31-40$ & 12 \\
$41-50$ & 19 \\
$51-60$ & 4 \\
$61-70$ & 2 \\
$71-80$ & 0 \\
$81-90$ & 4 \\
$91-100$ & 0 \\
$>100$ & 5 \\
\hline
\end{tabular}

\subsection{Stream Gauge Density}

Stream gauge density facilitates the identification of the minimum network required to avoid serious deficiencies in developing and managing water resources. The scale of this network is commensurate with the economic development and environmental needs of the country (WMO 2008).

WMO (2008) provides general guidelines on minimum stream gauge densities based on seven physiographic units. The recommendations do not consider social, economic, population density or other factors in network design. For Ontario, the physiographic unit used is the interior plain. The same physiographic unit has been previously used for Ontario (Pyrce 2004). In addition, as the study region is sparsely populated and rivers discharge into Hudson Bay, the stream networks for FNW, FNC1 and FNC2 of the OIH data package were evaluated for the polar regions as well. The gauge density recommended for interior plains is $1 / 1875 \mathrm{~km}^{2}$ and that for the polar region is $1 / 20000$ $\mathrm{km}^{2}$. The gauge density evaluated by WMO (2008) was calculated using the equation:

$$
S G D=\frac{D A}{N}
$$

where:

$$
\begin{aligned}
S G D & =\text { stream gauge density, area in } \mathrm{km}^{2} \text { per gauge }, \\
D A & =\text { watershed drainage, } \mathrm{km}^{2}, \text { and } \\
N & =\text { number of gauges. }
\end{aligned}
$$

Table 3 and Table 4 show the results of the analysis for each of the $\mathrm{OlH}$ watershed packages. None of the watersheds satisfied the WMO recommendation for stream gauge density of $1 / 1875 \mathrm{~km}^{2}$ for interior plains, which can potentially introduce much uncertainty into decision-making. The two watersheds FNC2 and FNC1 satisfied the recommended gauge density of $1 / 20000 \mathrm{~km}^{2}$ for polar regions.

Table 3 Results of stream gauge density.

\begin{tabular}{lccccc}
\hline \multicolumn{1}{c}{ OlH Package } & FNW & FNC2 & FNC1 & FNE & NW \\
\hline Total watershed area, $\mathrm{km}^{2}$ & 137941 & 187246 & 129702 & 150221 & 134388 \\
$\begin{array}{l}\text { No. of gauges } \\
\text { Stream gauge density (interior }\end{array}$ & 4 & 12 & 12 & 17 & 20 \\
plains), area in $\mathrm{km}^{2}$ per gauge & 34485 & 15604 & 10809 & 8837 & 6719 \\
Surface area drained, $\mathrm{km}^{2}$ & 36500 & 90710 & 121024 & 71356 & 68359 \\
Percentage surface area drained, $\%$ & 26 & 48 & 93 & 48 & 51 \\
\hline
\end{tabular}

Table 4 Summary of the results based on WMO (2008) recommendation.

\begin{tabular}{lccccc}
\hline \multicolumn{1}{c}{ OlH Package } & FNW & FNC2 & FNC1 & FNE & NW \\
\hline WM0(2008)_interior plains, area in $\mathrm{km}^{2}$ per gauge & 1875 & 1875 & 1875 & 1875 & 1875 \\
WM0(2008)_polar, area in $\mathrm{km}^{2}$ per gauge & 20000 & 20000 & 20000 & NA & NA \\
Northern 0ntario, area in $\mathrm{km}^{2}$ per gauge & 34485 & 15604 & 10809 & 8837 & 6719 \\
\hline
\end{tabular}

The percentage surface area drained was also estimated using the drainage area of each gauge. The value varied from a low value of $26 \%$ for FNW to a high value of $93 \%$ for FNC1. The high value for FNC1 is due to the downstream location of a gauge.

\subsection{Implementing the Concept of Virtual Gauges}

One of the initial network designs for stream gauging was suggested by Langbein in 1954. Our study implements his design for the discontinued gauges. A short description is given below.

A balanced stream gauging program consists of two elements: geographic sampling and time sampling. Geographic sampling is the process of determining the rate and volume of streamflow for different streams and at different locations on the same stream. Time sampling is for a point location of the stream reach and identifies the variations in the rate and volume of streamflow over time.

The basis of the design of a stream gauge network is the establishment of base stations to serve as fixed points for the time sampling factor, and of secondary gauges to operate for 
relatively shorter period for geographic sampling. Once a correlation has been established between a secondary gauge and the base gauge, then the secondary station is transferred to another stream reach for optimizing the hydrological information in space and time (Langbein 1954).

Since it is recognised that establishment of a complete network is impractical, this approach maximizes the information content in lieu of optimizing the economic value of data (WMO 2008). Further to that, if the reconstructed or synthesised data are of good quality, redundancy of information is reduced and diminishing returns are lessened.

We use the following naming convention. Base gauges are the active RHBN gauges or natural gauges with a long period of record. Virtual gauges are the secondary gauges and in, our case, the discontinued gauges.

Assume the virtual gauge $(y)$ has $n_{1}$ years of data and that the base gauge $(x)$ has $n_{1}+n_{2}$ years of data of which $n_{1}$ are concomitant (having a common period of record) with the observed data at the virtual gauge. This can be mathematically written as, for the base gauge:

$$
x_{1}, x_{2}, \ldots, x_{n_{1}}, x_{n_{1}+1}, x_{n_{1}+2}, \ldots, x_{n_{1}+n_{2}}
$$

and for the virtual gauge:

$$
y_{1}, y_{2}, \ldots, y_{n_{1}}
$$

For reconstructing the streamflow at the virtual gauge location, $y_{i}$ for the $n_{2}$ missing years of data, a simple linear regression equation of $y$ on $x$ can be used:

$$
y=m x+c
$$

where:

$$
\begin{aligned}
m & =\text { slope, } \text { and } \\
c & =\text { intercept. }
\end{aligned}
$$

\subsection{Steps in Reconstructing the Streamflow}

The steps required for the construction of the mean monthly flows are:

- delineate the homogenous regions;

select base gauge-virtual gauge pairs;

create correlations with the monthly mean and annual volumes of streamflow;

- estimate monthly mean streamflow values using the correlations; and

adjust the streamflow for annual volume.

Streamflow is typically characterized as a non-stationary parameter, since it changes in space and time. In other words streamflow is both non-homogeneous and anisotropic.

However, relative stationarity in time with isotropy and homogeneity of streamflow variation can be nearly achieved by the method of hydrological regionalization (WMO 1972) using homogeneous regions. The homogeneous regions for this study are the OIH data package polygons (OMNRF-OIH 2012), which are defined on a watershed basis (the ecosystem approach).

The base gauges selected are the RHBN gauges. If there is no RHBN gauge in the homogeneous region, or if a correlation with the RHBN gauge could not be established, then an active natural gauge with a long period of record was selected. Base gauge-virtual gauge selection from the same homogenous region minimizes climate variability and thereby achieves relative stationarity in time (WMO 1972).

In total 51 discontinued gauges were present in the region, as shown in the map (Figure 1 above). Initially, all gauges with $>10 y$ of record, with no zero flows, and that were not lake outlet gauges, in a drainage area provided by WSC, were selected. Usually RHBN and natural gauges have a stable flow, but the streamflow was also tested for change using the double mass curve. Figure 3 shows the double mass curve of HYDAT gauges 04CD002 and 04GB001. The gauge 04CD002 has relatively stable streamflow whereas the streamflow of 04GB001 has changed over time. Gauges with the double mass curve close to the equity line were selected.

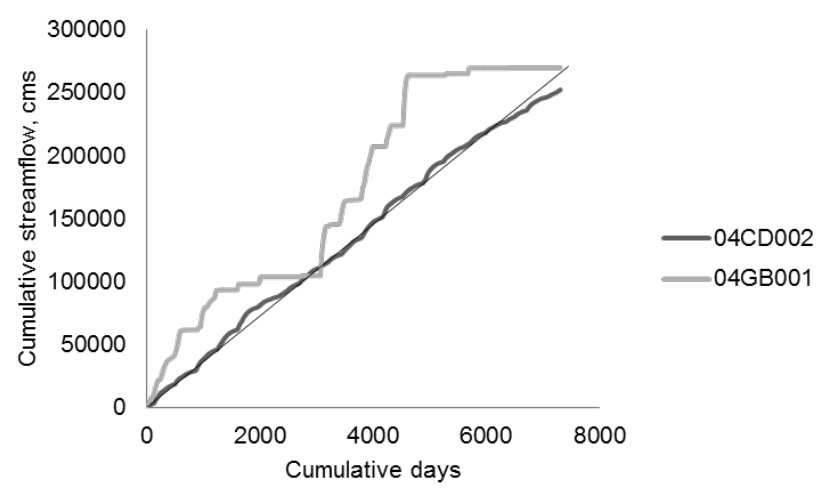

Figure 3 Double mass curve of 04CD002 and 04GB001.

The next step was to obtain the correct base gauge-virtual gauge pair. As stated above, gauges from the same homogenous regions were selected for the combinations. Then the timing of the monthly mean streamflow was tested by overlaying the base gauge-virtual gauge streamflow, as depicted in Figure 4. Final selection was based on the annual mean correlation coefficient. For this, correlations were established for monthly mean and annual volumes of streamflow. Winter streamflows are affected by ice and WSC reports it as B (backwater effect), so during these months the correlation is weak. A good fit was the basis of selection. From Figure 4, it can be seen that streamflow values fluctuate in step. Thus the value of the data diminishes as the gauges continue in operation. This means there is a diminishing return instead of an optimized economic value of the data, which illustrates one of the key principles required for network design with respect to funding. 


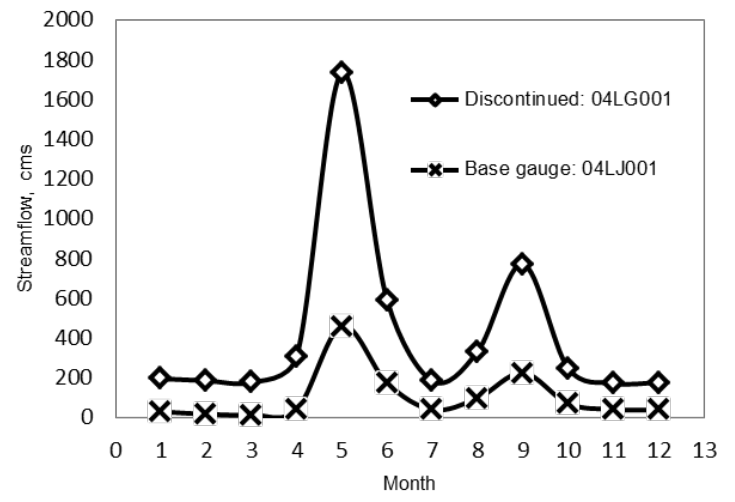

Figure 4 Graph to check the timing of streamflow.

Unlike temperature and precipitation, which are considered to be continuous, streamflow is considered to be discrete. A finite volume of water flows in a channel with a trapezoidal cross section every year. The rating curve (head-discharge) is a power function with changing slope at each point on the curve as the wetted perimeter is changing. Thus an equation is needed for the volume of water passing the location of the gauge on the stream reaches for each year. Volume correction was made by calculating the area under the curve using the trapezoidal rule and prorating the monthly mean value to the total volume from the regression equation. Furthermore, adjusting or correcting the annual volume removes the propagation of error down the time series.

Figures 5 shows the monthly mean correlated and volume corrected values of the streamflow of gauge 04JC003. The peak of the freshet hydrograph has improved with the volume correction whereas the peak of small events is overestimated. Nine virtual gauges were finally selected for reconstruction and the summary of the base gauge-virtual gauge combinations is given in Table 5 .

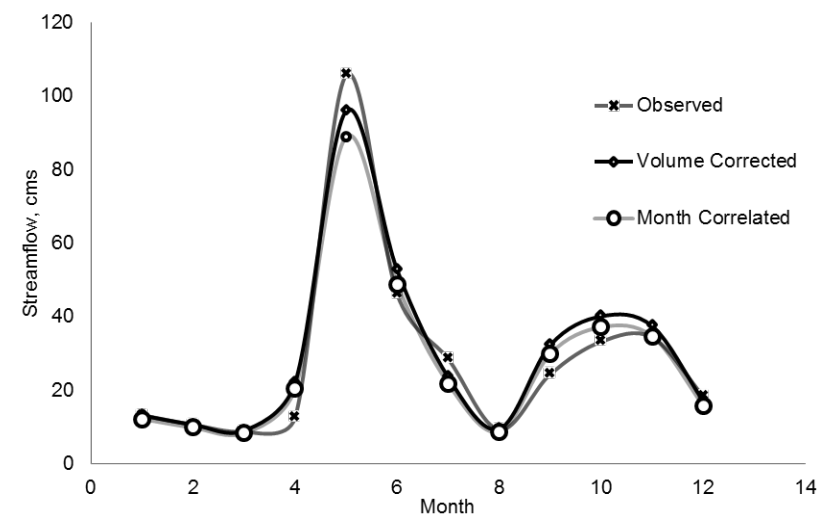

Figure 5 Monthly correlated mean monthly streamflow (gauge 04JC003).
Table 5 Information about base gauge-virtual gauges.

\begin{tabular}{lcclc}
\hline Base gauges & $\begin{array}{c}\text { Drainage area base } \\
\text { gauge, } \mathrm{km}^{2}\end{array}$ & RHBN & Virtual gauges & $\begin{array}{c}\text { Drainage area virtual } \\
\text { gauge, } \mathrm{km}^{2}\end{array}$ \\
\hline 04CA002 & 36500 & No & 04CCO01 & 94300 \\
& & & 04CDO02 & 4270 \\
04JC002 & 2178 & Yes & 04JA002 & 3780 \\
& & & 04JC003 & 3290 \\
04LJ001 & 8574 & Yes & 04LG001 & 34700 \\
& & & 04LG002 & 60100 \\
& & & 04LG003 & 34700 \\
04KA001 & 4250 & No & 04KA002 & 133 \\
05PB014 & 4768 & Yes & 050A001 & 13900 \\
\hline
\end{tabular}

\section{Results}

The locations of the reconstructed watersheds with the base gauge-virtual gauge locations are shown in Figure 6. As seen in the map, the reconstructed flows contain small, medium and large watersheds, with two gauges being nested. The drainage area of the virtual watersheds varied from $133 \mathrm{~km}^{2}$ to $94300 \mathrm{~km}^{2}$. This gives confidence in use of the methodology on a wider scale.

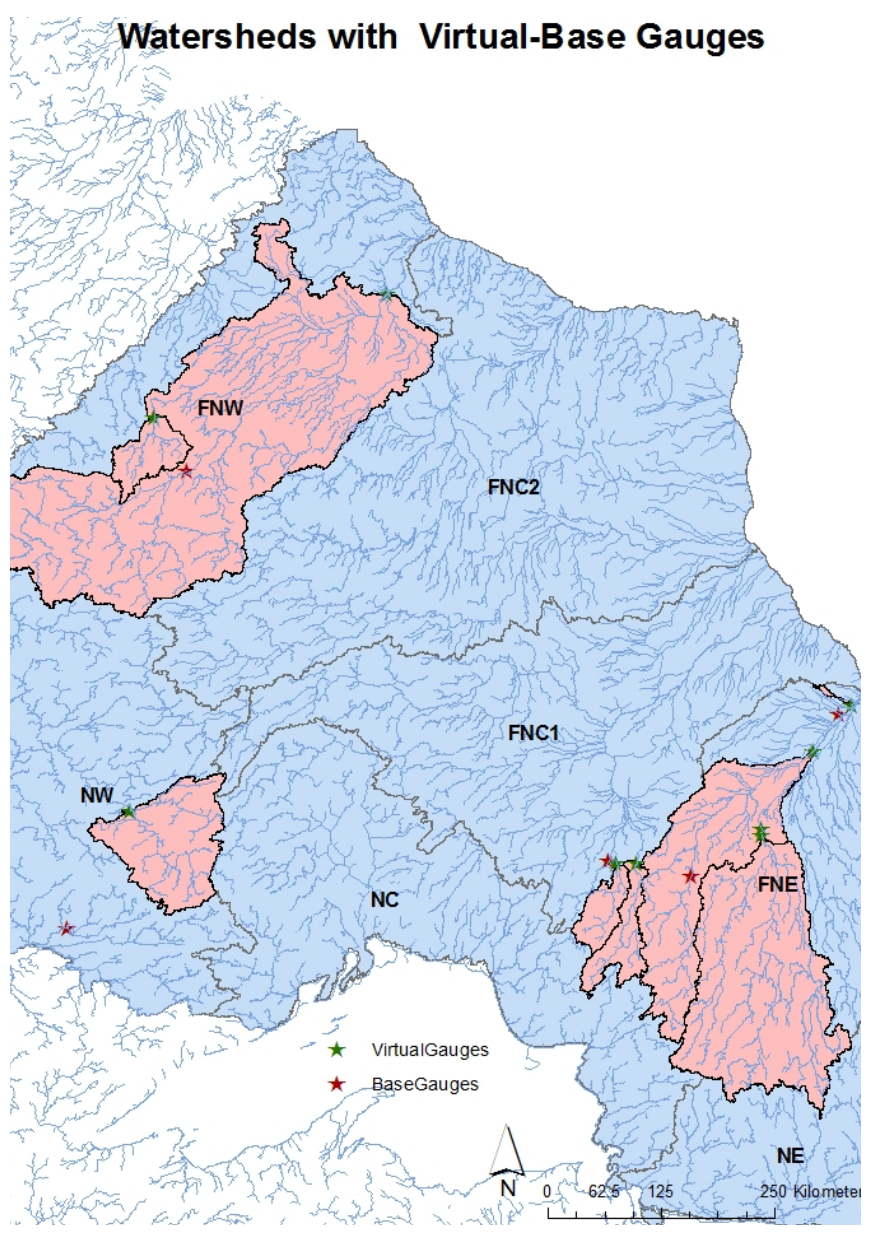

Figure 6 Map showing the watersheds and the locations of the base gauge-virtual gauges. 
Table 6 shows the summary of the results; the $R^{2}$ values are satisfactory except for the gauge 05PB014, which has a low value of 0.65 . The $R^{2}$ value is independent of the length of record and has no relationship with the distance between the gauges.

Table 6 Summary of the results of the analysis.

\begin{tabular}{lcccccc}
\hline Virtual gauges & $\begin{array}{c}\text { Distance } \\
\text { from base } \\
\text { gauge, } \mathrm{km}\end{array}$ & Start year & $\begin{array}{c}\text { Discontinued } \\
\text { year }\end{array}$ & No of years & $\begin{array}{c}\text { No of years } \\
\text { up to 2015 }\end{array}$ & $R^{2}$ \\
\hline 04CC001 & 296 & 1970 & 1994 & 21 & 34 & 0.86 \\
04CD002 & 70 & 1971 & 1991 & 20 & 33 & 0.8 \\
04JA002 & 31 & 1951 & 1986 & 36 & 65 & 0.95 \\
04JC003 & 10 & 1951 & 1986 & 36 & 65 & 0.95 \\
04LG001 & 94 & 1927 & 1962 & 36 & 37 & 0.97 \\
04LG002 & 194 & 1960 & 1982 & 23 & 89 & 0.97 \\
04LG003 & 90 & 1964 & 1994 & 31 & 56 & 0.93 \\
04KA002 & 18 & 1979 & 1997 & 19 & 52 & 0.93 \\
050A001 & 147 & 1922 & 1981 & 60 & 94 & 0.65 \\
\hline
\end{tabular}

The scatter plot of the observed and the predicted streamflows, the residual plot, and the superimposed time series plot of the observed and predicted streamflows for 04JA002 are shown in Figure 7 through Figure 9. This virtual gauge is correlated with the RHBN as a base gauge and shows good prediction of the time series.

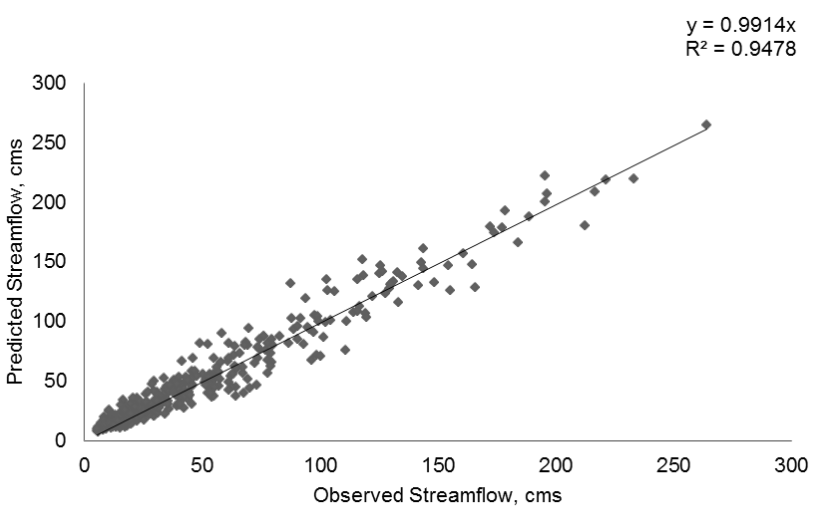

Figure 7 Predicted vs observed streamflow for gauge

\section{JA002.}

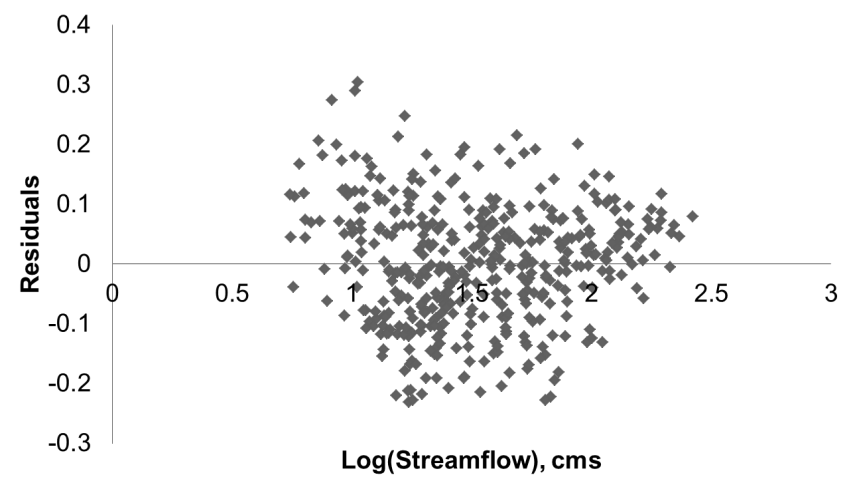

Figure 8 Residual of gauge 04JA002.

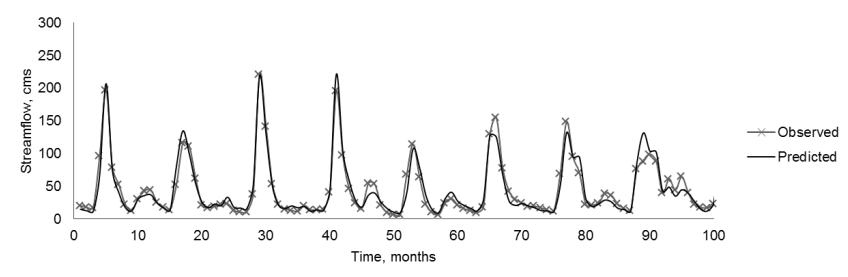

Figure 9 Time series of observed and predicted monthly streamflow of gauge 04JA002.

Virtual gauge 04CC001 is correlated (Figure 10) with the natural gauge as a base gauge. The time series plots (Figure 11) is more biased. This means that the reconstructed values gave good results when the relationship was established with the high quality RHBN gauges rather than the natural gauges.

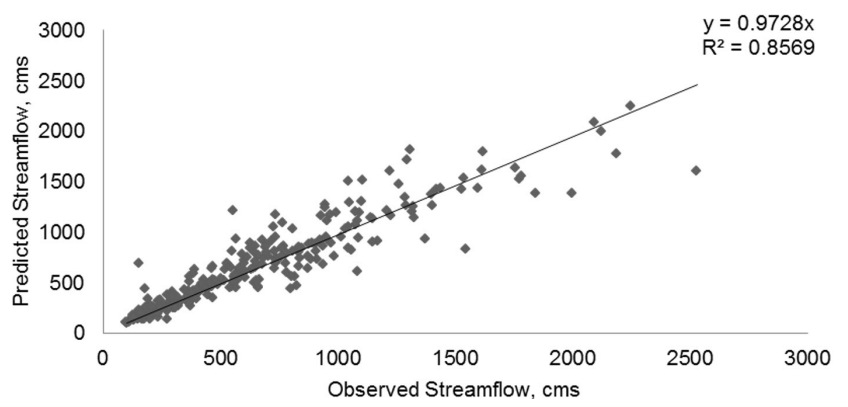

Figure 10 Predicted vs observed streamflow for gauge $04 \mathrm{CC} 001$.

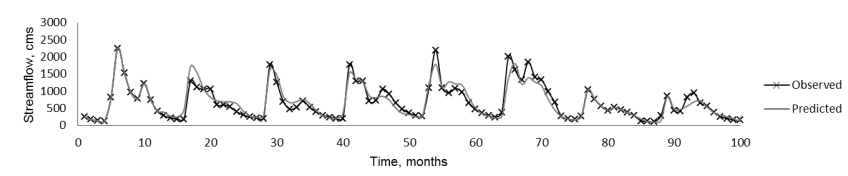

Figure 11 Time series of observed and predicted monthly streamflow of gauge $04 \mathrm{CC} 001$.

Streamflow data is positively skewed. The skew coefficients of the observed and predicted streamflows are given in the histogram (Figure 12). It is seen that the positive skews of the observed data are preserved. The histogram shows that the virtual gauges 04CC001, 04CD002 and 04KA002 each have lower skew. This is because the relationship was made with natural gauges (as base gauges) not with high quality RHBN gauges.

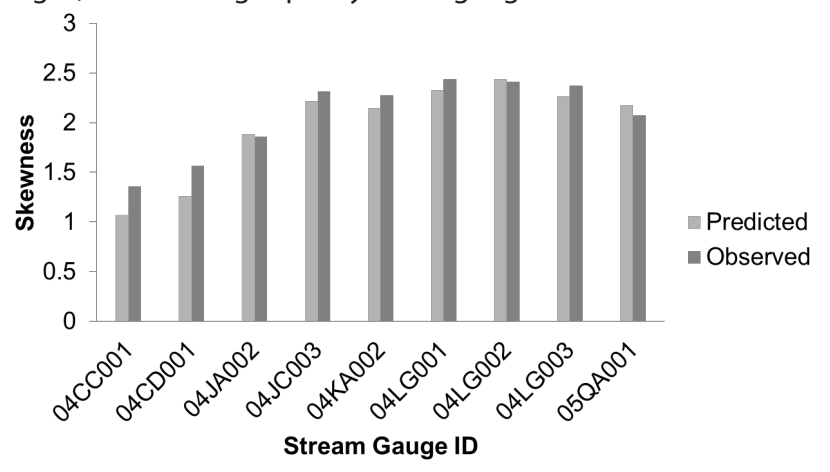

Figure 12 Skewness of the predicted and the observed streamflow. 
It is recommended that for robust network design the gauges 04CA002 and 04KA001 be brought up to the RHBN standards.

Figure 13 compares the mean annual flow of the observed and the combined (observed and constructed) flows. The graph shows a good fit with an $R^{2}$ value of 0.99 . The mean annual flow ranged from a low value of $1.6 \mathrm{~m}^{3} / \mathrm{s}$ to a maximum of $742 \mathrm{~m}^{3} / \mathrm{s}$. This large range in mean annual flow reflects the accuracy of the correlation in modeling small as well as large watersheds.

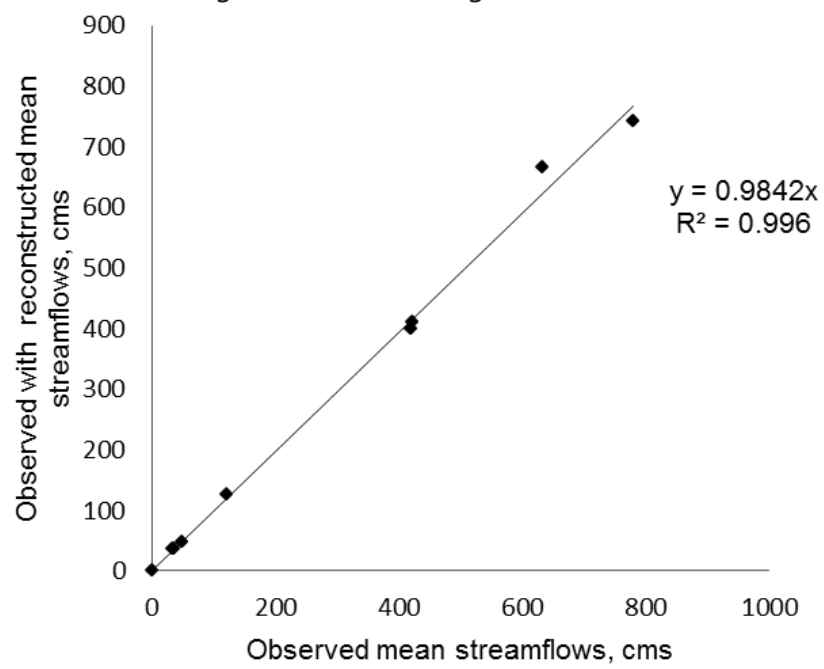

Figure 13 Comparison of mean annual flow of observed and combined (observed + predicted) streamflows.

As the number of gauges and the length of record increases in the region more information becomes available. The nine virtual gauges provide 282 station years of historic data. With reconstruction up to 2015, the station years of data became 525 , an increase of $53 \%$. Figure 14 shows the cumulative percentage of area drained for the active gauges and the combined (active and virtual) gauges.

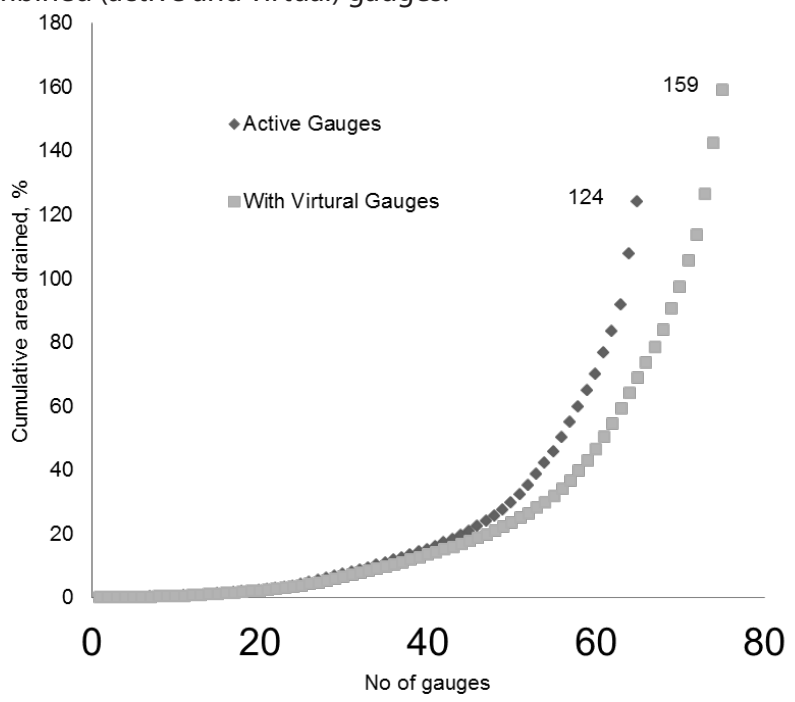

Figure 14 Comparison of cumulative percentage area drained.
The two curves have the same slope until the number of gauges is $\sim 40$. After that, the slope of the curve changes, with the cumulative percentage area drained increasing from 124\% to $159 \%$, showing the benefit of having higher spatial density in the network. Benefit-cost analysis of having more gauges in the network is beyond the scope of this study.

\section{Data Uses for Modeling}

Some of the uses and benefits of the nine virtual gauges with mean monthly values updated until 2015 are outlined in the following.

The data were compared in terms of suitability for modeling. The mean annual flow of the active gauges was regressed with the drainage area first and then the nine virtual gauge mean annual flows were incorporated into the dataset (see Figure 15). Neither the regression equation nor the value of $R^{2}(0.99)$ changed with the addition of the nine gauges. The values are within the range of variability of the active gauges. Mean annual runoff, the depth-equivalent discharge, is one of the main parameters used for any watershed modeling (e.g. regional flood flow and low flow regional models, design of structures, flood studies). Adding the data of nine gauges into the landscape increases the spatial density of the data, thereby increasing the quality of the parameter.

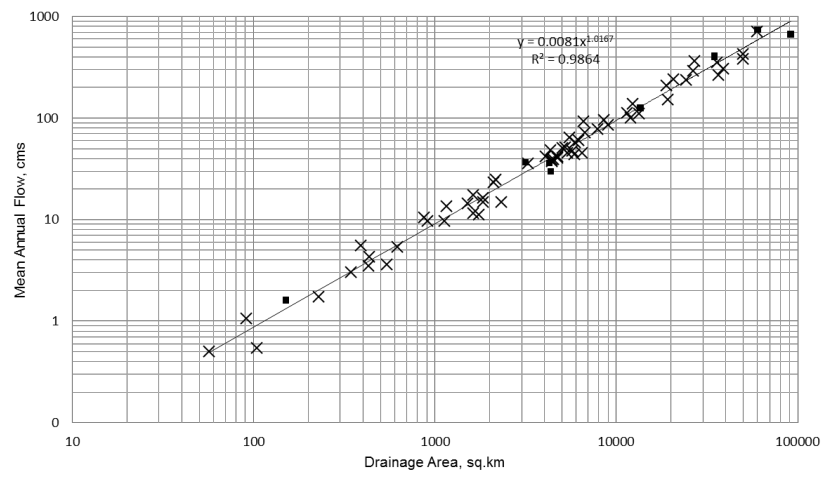

Figure 15 Comparing mean annual flow of the reconstructed and the active gauges in the study area (virtual gauges: solid dots).

The runoff coefficient is one of the key calibration parameters used in watershed modeling to transform precipitation into runoff. Annual and summer (July, August and September) runoff coefficients were taken from the previous study (OMNRF-SRB 2016) for the active gauges and then compared with the nine virtual gauges. There are no outliers and the values are within the range for the region. Runoff coefficients are shown in Figure 16 through Figure 19. 


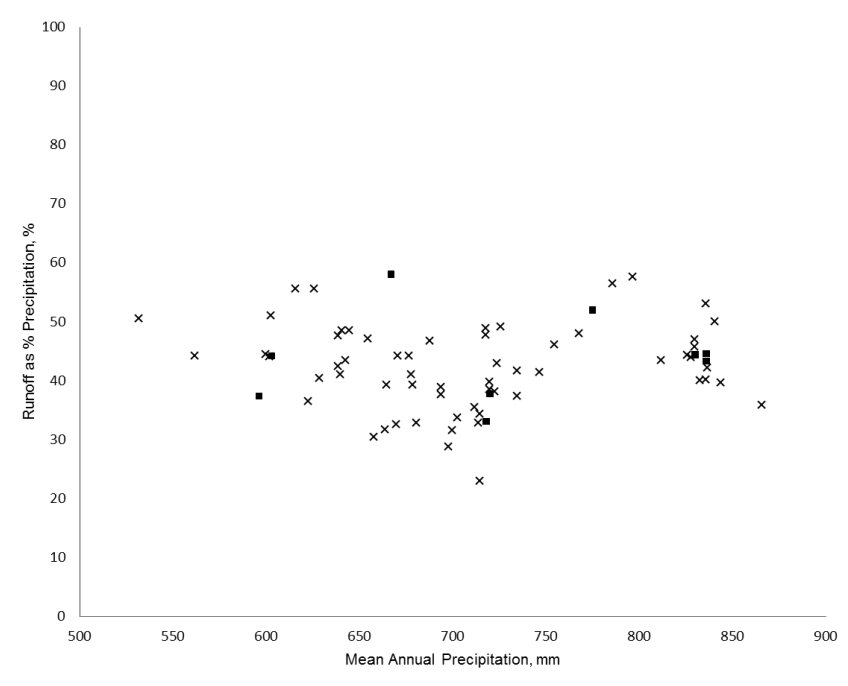

Figure 16 Mean annual runoff coefficient of active gauges with reconstructed values (virtual gauges: solid dots).

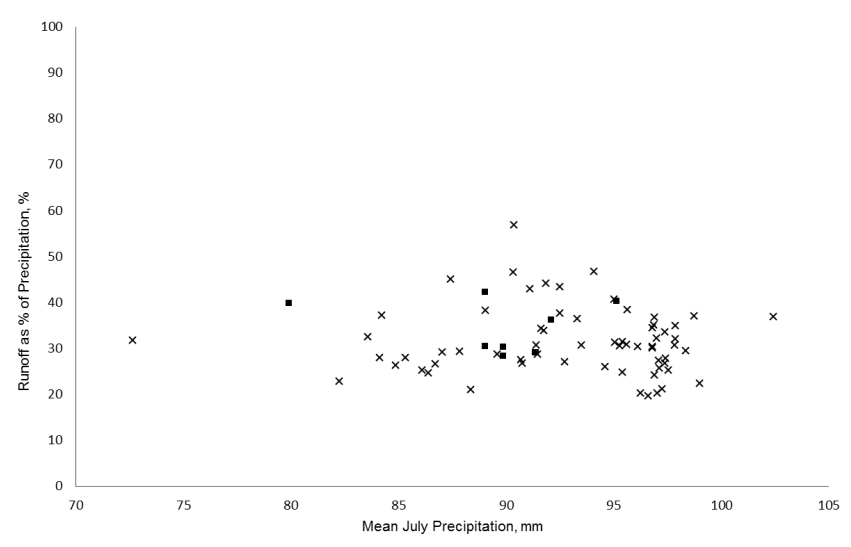

Figure 17 Mean July runoff coefficient of active gauges with reconstructed values (virtual gauges: solid dots).

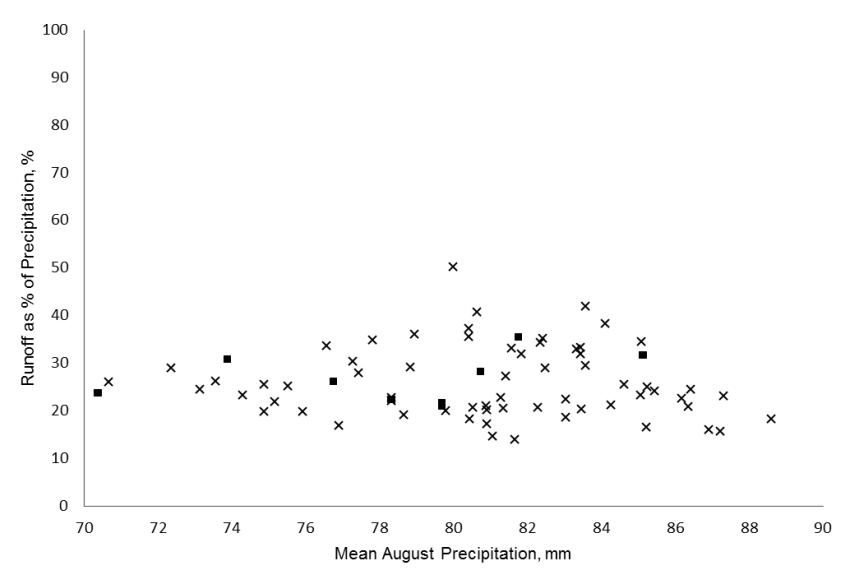

Figure 18 Mean August runoff coefficient of active gauges with reconstructed values (virtual gauges: solid dots).

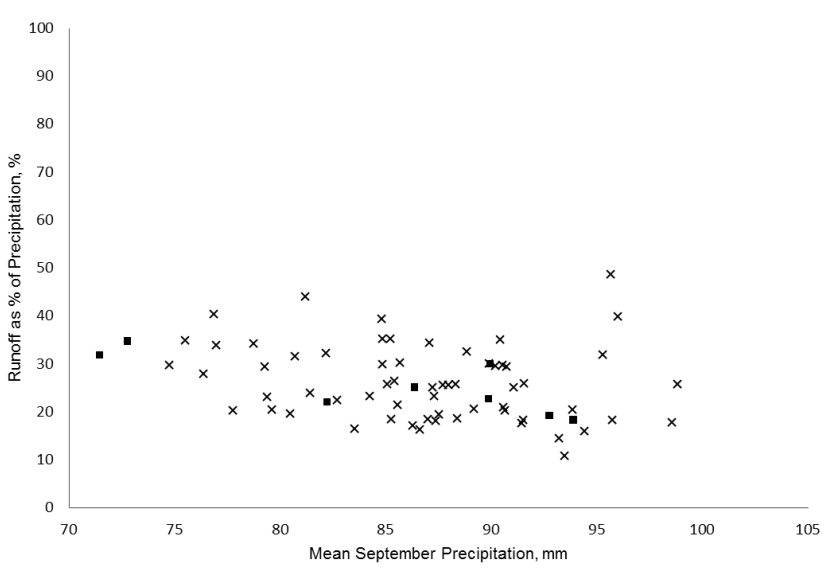

Figure 19 Mean September runoff coefficient of active gauges with reconstructed values (virtual gauges: solid dots).

The flow duration curve (FDC) is a versatile analytical tool used in water management studies. The FDC depicts the magnitude of flow as a function of percentage exceedance. The ratio, 10:90 percent flow exceedance, is used to estimate the streamflow variability. The observed and predicted values are shown in the histogram (Figure 20). The gauge 04KA002 has a higher difference than is shown by other gauges probably because the watershed drainage area is very small $\left(133 \mathrm{~km}^{2}\right)$.

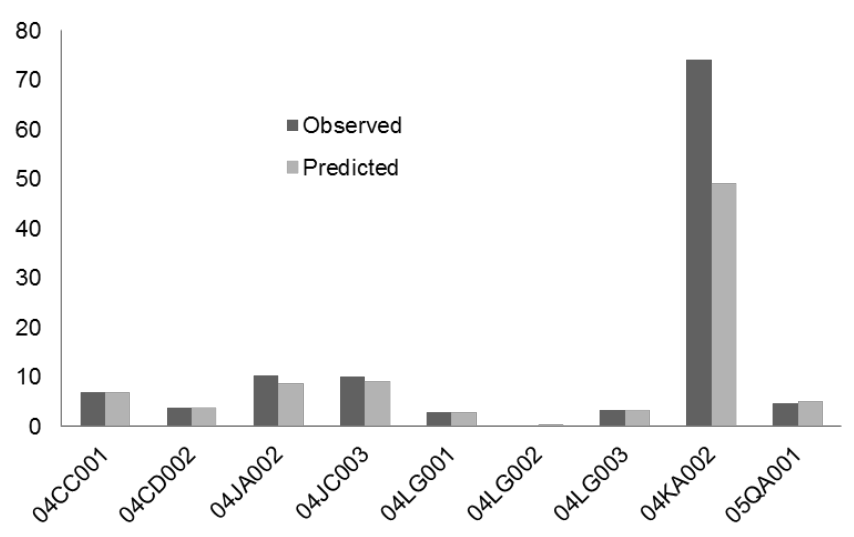

Figure 20 Flow duration curve, 10:90 exceedance ratio comparison.

The study area has very few recently-installed experimental groundwater monitoring wells. Groundwater availability in Northern Ontario has been studied (Singer and Cheng 2002) using the FDC derivative Sqrt $\left(Q_{25} / Q_{75}\right)$. This study compared the predicted and observed values (Figure 21 below) and showed no outliers.

The data are useful also for climate change studies as annual, seasonal and monthly mean streamflow values are used for detection and attribution (IPCC 2014).

These virtual gauges may be used as ground references to calibrate the satellite data; for example, the GRACE (ground 
recovery and climate experiment) satellite data includes monthby-month water mass changes.

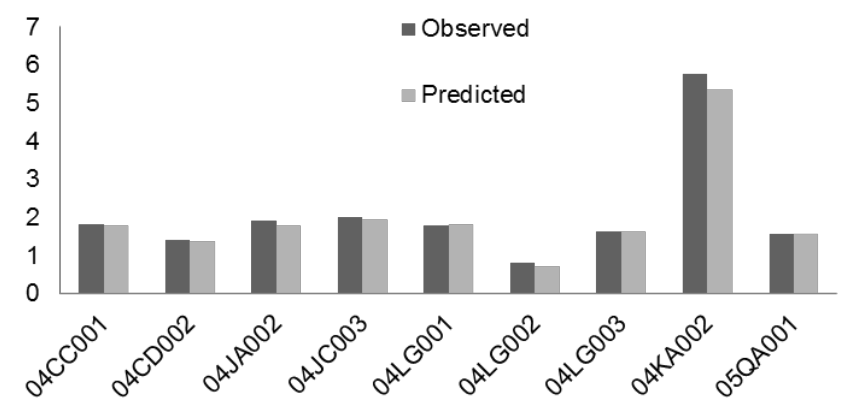

Figure 21 Flow duration curve, $\operatorname{Sqrt}\left(\mathrm{Q}_{25} / \mathrm{Q}_{75}\right)$ comparison.

\section{Conclusions}

Stream gauge density for the Northern Ontario stream gauge network was analysed using the $\mathrm{OlH}$ package, taking the watershed as the unit of analysis. None of the watersheds satisfied the minimum gauge density recommendation of WMO (2008) for interior plains. Watersheds FNC1 and FNC2 satisfied the minimum density recommendation for polar regions. Because much of Northern Ontario is consistent with the denotation interior plains rather than polar region, the recommendation is that a higher stream gauge density is required to provide valid science-based knowledge to facilitate land use planning in the region.

The study also applied the concept of virtual gauges in the network design. The virtual gauges were the discontinued gauges. It was shown that reconstructed values gave acceptable results when the relationship was established with the RHBN gauges rather than natural gauges. Hence adding more high quality (RHBN) gauges will bring unbiased data into this type of network design (daily flow from virtual gauges) and thereby reduce data needs.

With this type of network design two classes of information on streamflow can be obtained: relatively fixed or invariable characteristics such as unit hydrograph, routing coefficients and discharge curves; and time variable characteristics such as mean and volume duration curves. This network design improves the cost effectiveness of the network and optimizes the information.

The reconstructed data were tested for suitability of watershed modeling. The data can be combined with the data from active gauges in the same region showing homogeneity. It can be used for watershed modeling, climate change studies and also for calibrating satellite data.

\section{Acknowledgments}

The Far North Branch provided support for this project to the Science and Research Branch within the Ontario Ministry of Natural
Resources and Forestry as part of the Information and Knowledge Management project portfolio.

\section{References}

Azar, J., D. Sellars and D. Schroete. 2003. Water Quantity Monitoring in British Columbia: A Business Review of the BC Hydrometric Programs. Victoria, BC: British Columbia Ministry of Sustainable Resource Management. http://www.geoscientific.com/technical/tech_references_pdf_files/Water\%20Quantity\%20Monitoring\%20in\%20 BC.pdf

Coulibaly, P., J. Samuel, A. Pietroniro and D. Harvey. 2013. “Evaluation of Canadian National Hydrometric Network Density Based on WMO 2008 Standards." Canadian Water Resources Journal 38 (2): 159-67. https://doi.org/10.1080/07011784.2013.787181

Dillon Consulting Limited. 1996. Rationalization of Surface Water Monitoring Stations for Flood Management and Water Related Resource Management. Prepared for The Ontario Ministry of Natural Resources.

Environment Canada. 2010. Audit of the National Hydrometric Program. Ottawa: Environment and CLimate Change Canada. http://www.ec.gc.ca/ae-ve/default.asp?lang $=E n \& n=514 E 38 D 8-1$

Environment Canada. 2012. The Hydrometric Network. Ottawa: Government of Canada. https://www.canada.ca/en/environment-climate-change/ services/water-overview/quantity/monitoring/survey/hydrometric-program-national-partnership/network.html

IPCC (Intergovernmental Panel on Climate Change). 2014. Climate Change 2014: Impacts, Adaptation, and Vulnerability, edited by C. B. Field, V. R. Barros, D. J. Dokken, K. J. Mach, M. D. Mastrandrea, T. E. Bilir, M. Chatterjee, K. L. Ebi, Y. O. Estrada, R. C. Genova, B. Girma, E. S. Kissel, A.N . Levy, S. MacCracken,P. R. Mastrandrea and L. L. White. Cambridge: Cambridge University Press. Contribution of Working Group II to the Fifth Assessment Report of the Intergovernmental Panel on Climate Change.

Langbein, W. B. 1954. "Stream Gauging Network." In Proceedings of the International Association of Scientific Hydrology General Assembly of Rome 3, 293-303. International Association of Scientific Hydrology. Publication No.38, IAH

Mishra, A. K. and P. Coulibaly. 2008. "Developments in Hydrometric Network. Design: A Review." Reviews of Geophysics 47 (2). https://doi.org/10.1029/2007RG000243

OMNRF (Ontario Ministry of Natural Resources and Forestry). 2014. The Far North Land Use Planning Initiative. Toronto: Queen's Printer for Ontario. https://www.ontario.ca/page/far-north-land-use-planninginitiative 
OMNRF-OIH (Ontario Ministry of Natural Resources and ForestryOntario Integrated Hydrology). 2012. Integrated Hydrology Package. Toronto: Queen's Printer for Ontario. https://www.ontario.ca/data/ontario-integrated-hydrology-data

OMNRF-SRB (Ontario Ministry of Natural Resources and ForestryScience and Research Branch). 2016. Runoff Coefficient: For the Southwestern Hudson Bay and Nelson River Watershed Systems. Peterborough, Ontario: Ontario Ministry of Natural Resources and Forestry, Forest Research and Monitoring Section. https://www.javacoeapp.Irc.gov.on.ca/geonetwork? uuid=4280bcd7-068f-4260-8c23-7b1690deda8a

Pyrce, R. 2004. Review and Analysis of Stream Gauge Networks for the Ontario Stream Gauge Rehabilitation Project. Peterborough, Ontario: Trent University, Watershed Science Centre. WSC Report No. 01-2004. Prepared for the Ontario Ministry of Natural Resources and Forestry. https://www.trentu.ca/iws/documents/Network_Design_ Mar04.pdf

Shawinigan Engineering Company, Ltd. 1969. Planning of a Hydrometric Network for the Province of Ontario. Montreal, Quebec: Shawinigan Engineering Company, Ltd. Report 3728-1-69.
Singer, S. N and C. K. Cheng. 2002. An Assessment of the Groundwater Resources of Northern Ontario: Areas Draining Into Hudson Bay, James Bay and Upper Ottawa River. Toronto: Ontario Ministry of the Environment, Environmental Monitoring and Reporting Branch.

Whitfield, P. H, D. H. Burn, J. Hannaford, H. Higgins, G. A. Hodgkins, T. Marsh and U. Looser. 2012. "Reference Hydrologic Networks: I. The Status and Potential Future Directions of National Reference Hydrologic Networks for Detecting Trends." Hydrological Sciences Journal 57 (8): 1562-79. https://doi.org/10.1080/02626667.2012.728706

WMO (World Meteorological Organization). 1972. Casebook on Hydrological Network Design Practice. Geneva: World Meteorological Organization. WMO 324.

WMO (World Meteorological Organization). 1981. Guide to Hydrological Practices, vol I, 4th edn. Geneva: World Meteorological Organization.

WMO (World Meteorological Organization). 2008. Guide to Hydrological Practices, vol I, 6th edn. Geneva: World Meteorological Organization. WMO 168.

WSC (Water Survey of Canada). 2016. Water Survey of Canada. Ottawa: Environment Canada. https://wateroffice.ec.gc.ca 